\title{
Monitoring of visitors in museum exhibitions
}

\author{
Martin Drahanskýn ${ }^{1}$, Ivo Macek $^{2}$, Tomáš Goldmann ${ }^{1}$ \\ ${ }^{1}$ Brno University of Technology, Faculty of Information Technology, Božetěchova 2, 612 66, Brno, CZ; \\ \{drahan, igoldmann\}@fit.vutbr.cz \\ ${ }^{2}$ National Museum - Natural History Museum, Václavské náměstí 1, 110 00, Praha, CZ; ivo.macek@nm.cz
}

Drahanský M., Macek I. \& Goldman T., 2020: Monitoring of visitors in museum exhibitions. - Journal of the National Museum (Prague), Natural History Series 189: 155-162.

\begin{abstract}
The article describes historical and existing technologies for monitoring visitors in museum exhibitions. A proposal for a new solution is also included. These technologies mainly include wireless radio technologies (Wi-Fi, ZigBee, Bluetooth, UWB, RFID), while our idea of monitoring is based on the use of heat maps from camera images, i.e. processing of data from multiple camera sources.
\end{abstract}

Keywords: heat map, museum exhibition, monitoring, CCTV, Wi-Fi, ZigBee, Bluetooth, UWB, RFID

Received: October 14, 2020 | Accepted: November 20, 2020 | Published on-line: December 9, 2020

\section{Introduction}

Museums and galleries are an attractive environment in which the ability to track visitors with a view to understanding their behavior and preferred interest can be developed very well. This ambition began to develop significantly almost a hundred years ago, when Robinson published his work in 1928, and was followed by Melton (1935), Cohen et al. (1977), Rosenfeld (1982) and Bitgood \& Richardson (1987), with publications that focused on orientation, circulation and search of visitors' paths in zoos. In 1986, a peer-reviewed journal called Visitor Behavior appeared, and was published four times a year until 1997; since 2007, the journal has resumed publishing again, this time titled Visitor Studies. It is a periodical in which articles and example studies focusing on the behavior of selected groups of people from different countries and institutions are published.

Most research carried out on this topic has been carried out by the so-called "pencil and paper method", where the research teams observe visitors and their behavior is measured (timing) and recorded (tracking) in their forms. The second method has been the so-called "front-end evaluation", where the visitors are asked what they expect from the visit before entering the monitored area, and then are again asked when leaving whether their expectations have been met. The conference paper (Zancanaro et al. 2007) is based on the result of a sample of people in the museum using mobile guides. The purpose was to measure how long visitors would stay in the monitored area and how they would interact with the guide and information. Monitoring was carried out using infrared technology. As a result, time and percentage evaluation of the interaction of monitored visitors with the application in the 
monitored space was divided into clusters. In the thesis Kanda et al. (2007), the use of RFID chip technology was first described for this purpose. This approach brought a significant increase in the number of persons monitored (more than 8,000 in 25 days), and allowed visualization of their trajectory and so-called heatmaps - monitoring of positions of people at each defined time, which are summarized over the long term to create an overview of how often people were in a particular part of the monitored area, thus creating a clear image

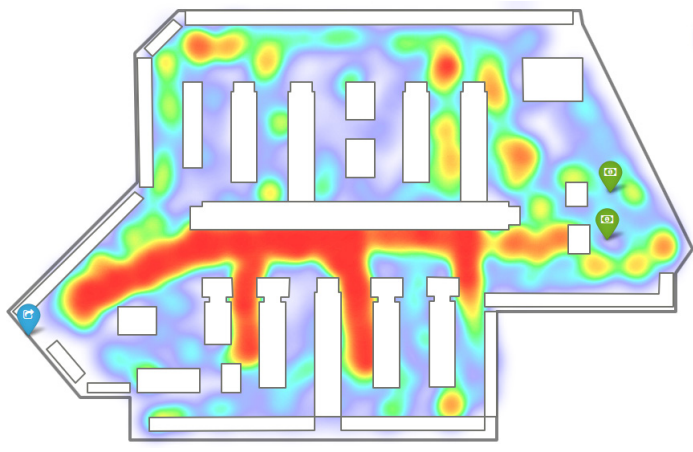

Fig. 1. Example of a heat map. of which parts of the exhibition are attractive for the visitors and which are less so (Fig. 1). ${ }^{1}$ In Yalowitz \& Bronnenkant (2009), the research team focused on observing people in the zoo using the paper and pencil method, where the output was a floor plan with percentages and times for individual parts of the exhibitions.

In 2017, the study [9] was published, which is focused on the issue of detecting the movement of people in enclosed spaces, the socalled in-house. Here again RFID chip technology was used, which is widely used in the commercial sector, for example in large shopping centers. The study (Lanir et al. 2017) was based on a visitor breakdown according to a study Véron \& Levasseur (1983), according to which the comparison of visitors to individual animals is defined into 4 categories: (a) ant - follows a precisely defined route and spends a lot of time in exhibitions; and usually avoids specific details, (b) butterfly - the visitor does not follow a specific path, but likes to navigate using physical pointers and stops more often for more information, (c) grasshopper - has specific preferences in the exhibition and spends more time studying them, and (d) fishes - flow slowly with a mainstream. The procedure was refined, but only 494 total persons were monitored.

Despite the effort to use these technologies, research by means of questionnaires or interviews is still the dominant way to gather selected information about visitors. Such research has its drawbacks, in particular in that it places increased demands on the staff doing the research, and the associated time-consuming analysis of the results. Today's trend in museums around the world is to be more visitor-oriented, making visitors feel comfortable in their spaces, and inciting them to return. Understanding visitors' behavior is thus crucial for working more efficiently with exhibited objects, their placement, protection and accurate comprehension of the interests of specific groups of visitors. The aforementioned works dealt with how long people stayed at a given point, how often they stopped, whether they liked the exhibition, and what was the age range and sex of the persons mo-

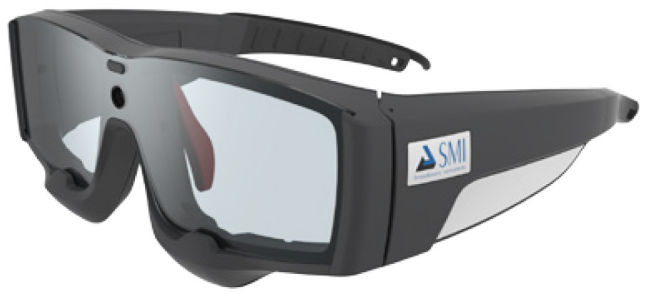

Fig. 2. SMI Eye Tracking Glasses 2 Wireless. ${ }^{2}$ always a short-term measurement on a limited number of visitors, due to the increased financial demands on technology (RFID) and the absence of other suitable available technolo-

1 https://www.retailflux.com/2018/05/07/investing-in-heatmap-analytics-in-retail-vs-traditional-digitalmarketing/ 
gies, as well as the difficulty of the number of people who physically collected questionnaire data. Moreover, the published procedures provide a relatively limited amount of valuable information: none of the studies dealt with the evaluation of visitors' behavior in the context of the protection of collections, or other elements of the exhibition related to them (models, dioramas, interactions, etc.), and so the protection of the institution's items. None of the aforementioned approaches dealt with whether the visitors to the exhibitions behave as they should, even if someone is not watching them, does not follow the stopwatch in their hands, does not ask any questions or does not carry an RFID chip on their neck.

\section{Existing technologies}

The aim of visitor monitoring is to gain an overview of how many people have visited the exhibition, how long they stayed in it, what routes they took, what time of day, what they were interested in and how they behaved in the exhibition area. A variety of technologies are used across museum institutions around the world, ranging from optical camera systems to radio transponder systems (RFID, Bluetooth, UWB, Wi-Fi). All these methods we can call Indoor Positioning System (IPS), where indoor GPS can be incorporated, and are used only for location accuracy.

\section{Monitoring visitors using cameras}

Analysis based on heat maps of the occurrence of people is often used in retail stores to optimize the distribution of goods. These maps show cold and hot areas, which indicate places where people do not stay and where they spend the most time (RatailFlux 2018). One of the companies that provides this solution on the market is RetailFlux. However, these solutions do not provide more comprehensive information about how people moved, where they went and what goods they looked at.

Another application of cameras in exhibitions is eye monitoring while observing the exhibit. This can bring us information about the person's interest in a particular exhibit. Once processed, this information can be used to interact with the user, for example by projecting accompanying text. In 2010, a solution was published that uses integrated cameras inside or outside the exhibit. A description of the solution can be found in Milekic (2010). This was the case when a user might not know that their view was being tracked. Another possible technology is based on special eye tracking glasses and is described in Yalowitz \& Bronnenkant (2009; see an example in Fig. 2). ${ }^{2}$

In general, there is no comprehensive system to monitor exposures using cameras. The closest thing to such a system is the application addressed in the thesis (Borggrewe 2013), where the student creates heat maps from camera images. From a technical point of view, older methods of computer vision are used in this work. Another way to track people in a confined space is to use a system based on infrared cameras.

\section{Monitoring visitors using wireless technologies}

Wireless monitoring is becoming increasingly popular, as it benefits both the operator and the visitor. The operator obtains information on the number of visitors to the monitored place (e.g. exhibition), how much time each visitor spent there and approximate positions where he stayed the longest. The visitor can also get information about where he is, and thus better navigate the space. Some wireless technologies work without active visitor involvement, such as Wi-Fi.

The location system typically consists of two parts: a beacon that sends information and a client device that processes the information. The disadvantage of this solution is the fact that the visitor must have some device (e.g. a mobile phone) that communicates with the beacons, or borrow it at the entrance.

Today, Wi-Fi is the most widespread wireless communication technology, and a major means of worldwide Internet traffic. The technology is based on the IEEE 802.11 standard

2 http://neuromarca.com/wp-content/material/2014/10/smi_etg2w_flyer.pdf 
and is managed by the Wi-Fi Alliance. Newer versions of Wi-Fi operate at $5 \mathrm{GHz}$, but still support $2.4 \mathrm{GHz}$ for backward compatibility (Shaw 2018). Wi-Fi technology has been used in many localization systems. Wi-Fi has become an attractive technology for localization systems due to its great expansion, price and availability. The vast majority of Wi-Fi localization researchers work with RSS (Received Signal Strength). The first system to start Wi-Fi localization was RADAR, from Microsoft Corporation (Yu et al. 2016). Large museums, such as the National Gallery and the Natural History Museum in London and the National Railway Museum in NYC, are already using Wi-Fi to track visitors to see which exhibits are the most popular. This information then helps to improve the organization of exhibitions and reduce overcrowding. The system only uses the signal from visitors' phones, even if they are not connected to the network; it is sufficient to have Wi-Fi enabled. Each phone is then displayed as a colored dot in the system. The more dots appear in one place, the more intensely it is shown on the resulting map (Milekic 2010).

ZigBee communication technology is described in the IEEE 802.15.4 standard, managed by the ZigBee Alliance. ZigBee is a simple and flexible technology designed to create large networks with little data transfer. Its advantage is that it creates low-cost personal networks with low power consumption and is used, for example, in many industrial applications especially where competing Bluetooth and Wi-Fi technologies are not suitable. Today it is used in industrial and home automation, healthcare and other areas (Bellido-Outeirino et al. 2012). ZigBee operates mainly at $2.4 \mathrm{GHz}$ or $868 \mathrm{MHz}$, but also allows other frequency bands. For localization purposes, signal strength (RSS) is used, which changes in motion similarly to other technologies operating at $2.4 \mathrm{GHz}$. This information is then used for calculation in multilateration or fingerprinting (Bianchi et al. 2018). The main drawback is that ZigBee technology is the most commonly used in the Bluetooth and Wi-Fi frequency bands, which severely interfere with each other, so it is not appropriate to use ZigBee where these competing technologies are already in use. Another shortcoming is the absence in mobile phones. The operator would have to purchase client hardware that the visitor would borrow.

Bluetooth is a low-energy wireless technology based on the IEEE 802.15.1 standard operating at $2.4 \mathrm{GHz}$. This technology is primarily designed for short distances (tens of meters), e.g. for computer accessories such as mice, keyboards, headphones, etc. Its range depends mainly on the power consumption of the device and the Bluetooth standard used. It is a popular technology in the area of localization systems. For this purpose, a beacon (beacon, transmitter) is used, which transmits information packets to the Bluetooth network at given intervals. Depending on the strength of the received signal, it is possible to obtain an approximate distance between the receiver (client) and the beacon. By using several transmitters it is possible to determine the position of the client device using trilateration and fingerprinting methods. In the optimum case (the same transmit power of all beacons) an accuracy of up to $1 \mathrm{~m}$ can be achieved (Zhao et al. 2018). In this way, Bluetooth is already being used in the American Museum of Natural History in NYC. The visitor is allowed to download the application to their mobile phone, where they can choose areas of interest or specific exposure. The application will find out the current location of the visitor according to the surrounding Bluetooth beacons and offer them the best route according to their requirements. There are 700 beacons throughout the building (internet sources: Bluetooth beacons 2015, Beacons in museums 2020). Another example of a practical deployment of this technology is tracking people's trajectories in the French Louvre Museum, where, based on data obtained from a Bluetooth-based system, they found that the behavior of people who stay long in the museum compared to people who do not stay in the museum for too long is similar (Yoshimura et al. 2014).

Ultra-Wideband (UWB) is a technology based on sending short pulses through a wide band of radio spectrum from $3.1 \mathrm{GHz}$ to $10.6 \mathrm{GHz}$. The signal is transmitted for a much shorter time than RFID, which brings the advantage of lower power consumption and allows fil- 
tering of the reflected signal, increasing accuracy. For example, Ubisense and Sewio ${ }^{3}$, which offer a real-time positioning system based on UWB technology, introduced the real use of this technology. UWB employs time-synchronized communication techniques, providing very accurate real-time localization with centimeter accuracy (Gu et al. 2009). This technology is deployed at the Snorrastofa Reykholt Museum, where they use a hybrid GPS and UWB system. Each visitor is provided with an audio guide that provides location-specific content based on location. Upon entry, the visitor borrows a locator that connects to his/her phone via Bluetooth and can see where he/she is, with additional exposure information on the map (within $20 \mathrm{~cm}$ accuracy). Many global companies are now seeking to obtain this solution from Locatify for their museums and music exhibitions (Swedberg 2017).

Radio Frequency Identification (RFID) is used for automatic identification using radio waves. The system consists of two components: an RFID reader and an RFID tag. The tag can be active, generating impulses itself, or passive, when the tag uses the energy from the RFID reader and responds with its identification number. Readers are generally more expensive because they contain an antenna, processor, power supply, internet connection, etc. On the other hand, the tag contains only a simple chip with an identification number and an antenna (Alarifi et al. 2016). Most often, this technology is used in warehouses to record assets. Either the tagged objects move around the gate with an integrated RFID reader, or they are scanned manually by the operator. However, due to the short range (up to approximately one meter), this technology is not suitable for tracking people (Liu 2007). Nevertheless, this technology is used in the National Museum of Mathematics in NYC. Visitors need to carry an RFID tag, which means they know they are tracking. Installing such a system is costly, especially because of the required infrastructure, but RFID systems are generally very reliable (Mateo 2014).
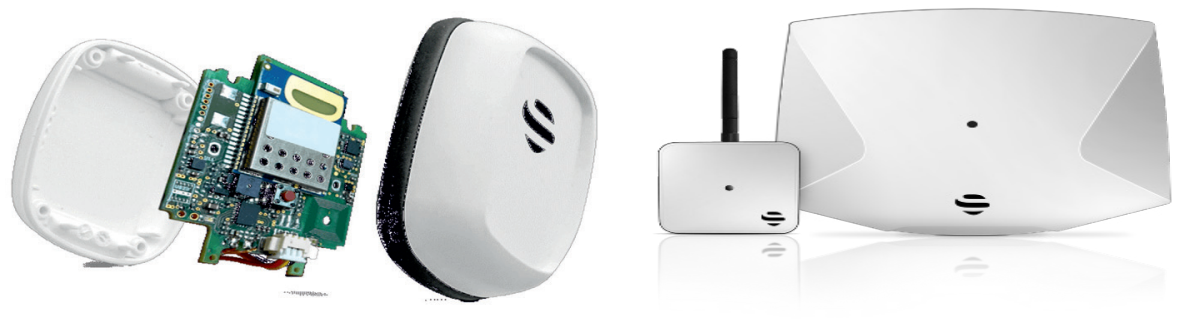

Fig. 3. Sewio solution. ${ }^{3}$

\section{Ideas to extend the suitability of existing technologies}

Said wireless technologies (RF technologies) generally operate on the transmitter-receiver principle. One device is static and therefore we know its exact position; the other moves, and the position of the dynamic device is calculated using signals received at the static devices and processed by positioning algorithms. Measurements and calculations take place at regular intervals, and these positions of specific devices are stored in the database. If we want to graphically display the occurrence / movement of visitors, we select data from the database for a given time interval (e.g. day) and we represent all this data on the plan of the monitored space. As a result, we get a so-called heat map where the most visited place will represent the hot class. Warm color, e.g. red, is most often used for this representation, and blue for cold areas. Museum or gallery operators will thus be informed about which exposures visitors find interesting and which are less frequented Lanir et al. 2017).

3 https://www.sewio.net/ 


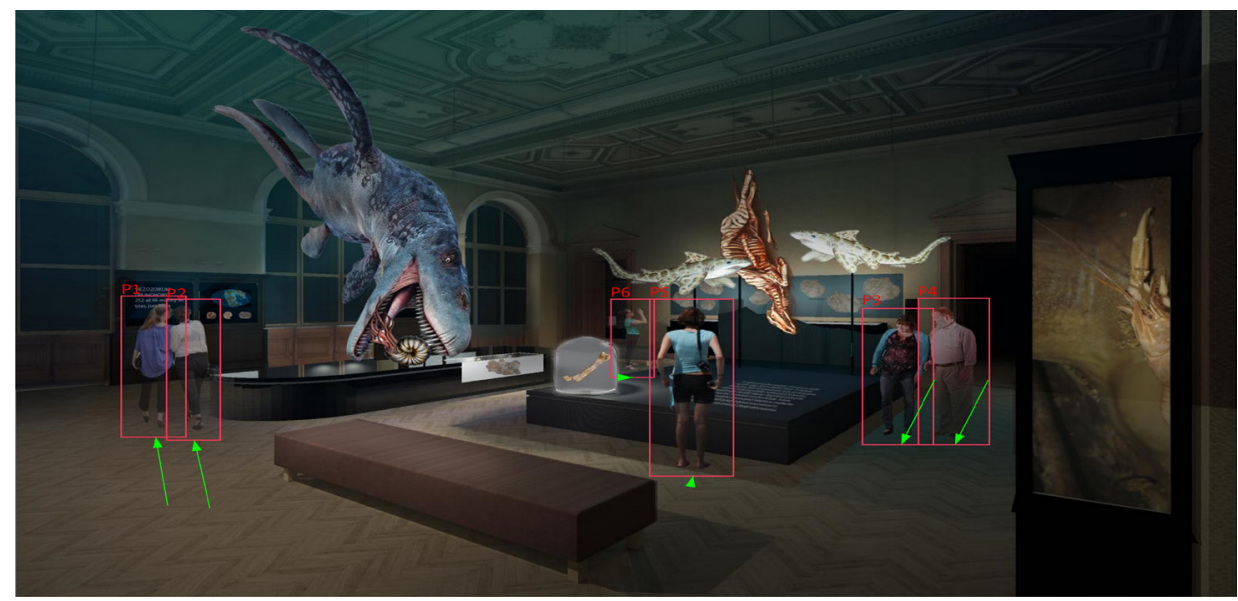

Fig. 4. Visualization of persons tracking in National Museum using CCTV. Author: Ing. arch. D. Kříž.

The technology of automatic monitoring of visitors to the exhibitions based on cameras, whether CCTV (Closed-Circuit Television) or others, is not commonly used in practice, although it has indisputable advantages over other technologies. First of all, it is not necessary for visitors to have a device that receives signals, such as a cell phone, or some type of audioguide or chip. An example of a practical deployment of exposure solutions that use cameras is a manual tracking system, but it works by recording the behavior of a visitor or group of visitors based on the playback. Speaking of automatic evaluation, experiments were carried out to monitor one room with one camera (Yalowitz \& Bronnenkant 2009). Retailers use data from CCTV cameras to create heat map of buyer behavior. They are mostly generic analytical tools without focus. For museums and similar institutions there is not yet a specialized system for evaluating visitors' behavior. With the development of new machine learning methods and sufficient computing power, new opportunities for creating new visitor monitoring and automated data analysis systems are opening up.

On the basis of the findings we can say that the development of camera-based systems has great potential. The main advantage is that it is not necessary to secure cooperation of the exhibition visitor, who may not even know about the analytical evaluation. That is one of the great benefits, because the so-called Hawthorne effect is eliminated (user knows that they are part of an experiment and behaves unnaturally).

At the same time, we are able to recognize certain behaviors and movements, and focus in more detail on the visitors' behavior. The utilization of the heat map is therefore an essential element for recognizing the more frequented parts of the visitor spaces. The technology of combining several types of cameras together with specific software enables us to obtain passively a much wider spectrum of objective data on visitor behavior/interaction in exhibitions than the above mentioned technologies, while at the same time the whole process can be realized in accordance with GDPR regulation and privacy.

Our ideas for extending the suitability of existing technologies come with an innovative non-invasive solution that allows long-term data collection without the need for personnel and, above all, allows passive monitoring, where the visitor does not know that he/she is being monitored and thus behaves quite naturally. In addition, the spectrum of data collected will allow for much more objective and wider use than previously published procedures. A range of software solutions will operate several specially adapted CCTV technologies to detect people at the entrance to the exposure and automatically analyze their behavior anonymously. It will then be possible to pose questions like: Are visitors concerned with subjects that are not intended for visitor interaction? Do they find their way to all the designated areas 
intended for exhibitions? Do children stay on the edges of open dioramas or do they enter them? Are flashes being used on light-sensitive exhibits? Are there dangerous accumulations of people in certain parts of the exposure, or in interactions between lecturers and school groups? Which target groups are interested in which parts of the exposure with regard to age, type of group, gender or nationality?

The development of computer technology and the wide availability of individual camera modules makes it possible to develop a given technological solution so that it can be used at any exhibition in any museum or similar institution, plus an economic structure that ensures its easy accessibility. The methodology for how to collect, process and evaluate the data in order to increase the effectiveness of exhibitions and exhibitions with regard to the protection of exhibits and installations exhibited, as well as the effectiveness of presentation to the visitor, could then be prepared (see the visualization on Fig. 4). This is an innovative approach that has not yet been implemented anywhere in the world, and therefore we intend to work on it.

\section{Acknowledgement}

This work was supported in part by the Ministry of Culture of the Czech Republic (DKRVO 2019-2023/26.II.a, National Museum, 00023272) and partially in the scope of the project "Research and education of citizens of the Czech Republic in the field of biometrics" TL02000134 supported by the Technology Agency of the Czech Republic. We also thank the reviewers: Adam Cironis (National Museum, Prague) and Jakub Hrabec (CEITEC, Brno University of Technology) for their valuable comments and corrections.

\section{References}

Alarifi A., Al-Salman A., Alsaleh M., Alnafessah A., Al-Hadhrami S., Al-Ammar M., Al-Khalifa H.2016: Ultra wideband indoor positioning technologies: Analysis and recent advances. - Sensors 16, 5: 707. https://doi.org/10.3390/s16050707

Bellido-Outeirino F., Flores-Arias J., Domingo-Perez F., Gil-de-Castro A., Moreno-Munoz A., 2012: Building lighting automation through the integration of DALI with wireless sensor networks. - IEEE Transactions on Consumer Electronics 58, 1: 47-52. https://doi. org/10.1109/tce.2012.6170054

Bianchi V., Ciampolini, P., De Munari I., 2018: RSSI-based indoor localization and identification for ZigBee wireless sensor networks in smart homes. - IEEE Transactions on Instrumentation and Measurement 68, 2: 566-575. https://doi.org/10.1109/ tim.2018.2851675

Bitgood S., Richardson, K., 1987: Wayfinding at the Birmingham Zoo. - Visitor Behavior 1, 4: 9. Borggrewe S., 2013: Movement analysis of visitors using location-aware guides in museums. - Master's thesis, RWTH Aachen University, University of Edinburgh, Aachen. 98 pp.

Cohen M.S., Winkel G.H., Olsen R., Wheeler F., 1977: Orientation in a museum - An experimental visitor study. - Curator: The Museum Journal 20, 2: 85-97. https://doi. org/10.1111/j.2151-6952.1977.tb00923.x

Gu Y., Lo A., Niemegeers I., 2009: A survey of indoor positioning systems for wireless personal networks. - IEEE Communications surveys \& tutorials 11, 1: 13-32. https://doi. org/10.1109/surv.2009.090103

Kanda T., Shiomi M., Perrin L., Nomura T., Ishiguro H., Hagita N., 2007: Analysis of people trajectories with ubiquitous sensors in a science museum. - Proceedings 2007 IEEE International Conference on Robotics and Automation, Roma: 4846-4853. https://doi. org/10.1109/robot.2007.364226

Lanir J., Kuflik T., Sheidin J., Yavin N., Leiderman K., Segal M. 2017: Visualizing museum visitors' behavior: Where do they go and what do they do there? - Personal and Ubiquitous Computing 21, 2: 313-326. https://doi.org/10.1007/s00779-016-0994-9 
Liu H., Darabi H., Banerjee P., Liu J. 2007: Survey of wireless indoor positioning techniques and systems. - IEEE Transactions on Systems, Man, and Cybernetics, Part C (Applications and Reviews) 37, 6: 1067-1080. https://doi.org/10.1109/ipin.2016.7743591

Mateo A.S., McConnell Ch.L., Schutes J.T. \& Velasquez P.J.E., 2014: Refining Visitor Tracking for Museum Victoria. - Retrieved from https://digitalcommons.wpi.edu/iqp-all/773. 71 pp. [Accessed on 10 October 2020]

Melton A.W., 1935: Problems of installation in museums of art. - Washington, D.C.: American Association of Museums, 276 pp. https://doi.org/10.1037/11526-000

Milekic S., 2010: Gaze-tracking and museums: Current research and implications. - In: Trant J., Bearman D. (eds): Museums and the Web 2010: Proceedings. Toronto: Archives \& Museum Informatics. http://www.archimuse.com/mw2010/papers/milekic/milekic. html [Accessed on 10 October 2020]

Robinson E.S., Sherman I.C., Curry, L.E., Jayne H.H.F., 1928: The Behavior of the Museum Visitor. - Washington, D.C.: American Association of Museums, 71 pp.

Rosenfeld S., 1982: A Naturalistic Study of Visitors at an Interactive Mini-Zoo. - Curator: The Museum Journal 25, 3: 187-212. https://doi.org/10.1111/j.2151-6952.1982.tb00593.x

Shaw, K., 2018: 802.11x: Wi-Fi standards and speeds explained. - Network World. https:// www.networkworld.com/article/3238664/80211x-wi-fi-standards-and-speedsexplained.html [Accessed on 10 October 2020]

Véron E., Levasseur M., 1983: Ethnographie de l'exposition: L'espace, le corps et le sens. Paris: Bibliothèque publique d'information - Centre Georges Pompidou, 178 pp.

Yalowitz S.S., Bronnenkant K., 2009: Timing and tracking: Unlocking visitor behavior. - Visitor Studies 12, 1: 47-64. https://doi.org/10.1080/10645570902769134

Yoshimura Y., Sobolevsky S., Ratti C., Girardin F., Carrascal J.P., Blat J., Sinatra R., 2014: An analysis of visitors' behavior in the Louvre Museum: A study using Bluetooth data. - Environment and Planning B: Planning and Design 41, 6: 1113-1131. https://doi. org/10.1068/b130047p

Yu Ch., Li X., Dou L., Li J., Zhang Y., Qin J., Sun Y., Cao Z., 2016: Implement and Optimization of Indoor Positioning System Based on Wi-Fi Signal. - In: Carretero J., Garcia-Blas J., Ko R., Mueller P., Nakano K. (eds): Algorithms and Architectures for Parallel Processing. ICA3PP 2016. Lecture Notes in Computer Science. Vol. 10048: 220-228. Cham: Springer. http:// doi-org-443.webvpn.fjmu.edu.cn/10.1007/978-3-319-49583-5_17

Zancanaro M., Kuflik T., Boger Z., Goren-Bar D., Goldwasser D., 2007: Analyzing museum visitors' behavior patterns. - In: Conati C., McCoy K., Paliouras G. (eds): User Modeling 2007. UM 2007. Lecture Notes in Computer Science. Vol. 4511: 238-246. Berlin, Heidelberg: Springer. https://doi.org/10.1007/978-3-540-73078-1_27

Zhao X., Ruan L., Zhang L., Long Yi, Cheng F., 2018: An Analysis of the Optimal Placement of Beacon in Bluetooth-INS Indoor Localization. - In: Kiefer P, Huang H., Van de Weghe N., Raubal M. (eds): Adjunct Proceedings of the $14^{\text {th }}$ International Conference on Location Based Services. Pp. 50-55. ETH Zurich. https://doi.org/10.3929/ethz-b-000225588

\section{Internet sources}

Bluetooth beacons help navigate museum halls. The American Museum of Natural History, 2015. https://www.amnh.org/explore/news-blogs/news-posts/bluetooth-beaconshelp-navigate-museum-halls [Accessed on 10 October 2020]

Beacons in museums. BeaconZone, 2020. URL: https://www.beaconzone.co.uk/blog/ beacons-in-museums/ [Accessed on 10 October 2020]

RetailFlux. Applications of heatmap analytics in retail: Maximizing store layout - retailflux | exclusive in-store analytics, 2018. https://www.retailflux.com/2018/05/21/ applications-of-heatmap-analytics-in-retail-maximizing-store-layout/ [Accessed on 10 October 2020]

Claire Swedberg. UWB technology proves mythological for Icelandic museum, 2017. https:// www.rfidjournal.com/articles/view?16932 [Accessed on 10 October 2020] 